\title{
First Records of the Common Leopard Gecko, Eublepharis macularius (Blyth 1854) (Eublepharidae), in Nepal
}

\author{
Yam Bahadur Rawat ${ }^{1}$, Kul Bahadur Thapa ${ }^{2}$, Santosh Bhattarai ${ }^{3}$, and Karan Bahadur Shah ${ }^{2}$ \\ ${ }^{1}$ Department of National Parks and Wildlife Conservation, Shuklaphanta National Park, Kanchanpur, Nepal \\ ${ }^{2}$ Himalayan Nature, POB- 10918, Lazimpat, Kathmandu, Nepal \\ ${ }^{3}$ National Trust for Nature Conservation-Biodiversity Conservation Center, Ratnanagar-06, Chitwan-44204, Nepal (santosh.bhattarai@hotmail.com)
}

Esix yelid Geckos (Eublepharidae) are represented globally by six genera and 38 species (Uetz et al. 2018) that have a collective pan-tropical/subtropical distribution across North and Central America, western and eastern Africa, the Middle East, and southern, southeastern, and far eastern Asia (Ota et al. 1999). The earliest records for the genus Eublepharis are from Afghanistan, Bangladesh, India, Iran, Iraq, Pakistan, and Turkmenistan. The Common Leopard Gecko (Eublepharis macularius) is a secretive, ground-dwelling, nocturnally active gecko that has been reported to occur in arid habitats of Afghanistan, northwestern India, and Pakistan (Bonke et al. 2011). Herein we report the first Nepalese country records for this species, genus, and family, which is the eleventh species of gecko known to occur in Nepal.
At 1625 h on 30 December 2016, we encountered two male Common Leopard Geckos (Eublepharis macularius; Fig. 1) hibernating $1.5 \mathrm{~m}$ above the ground under the bark of a dead standing Asna Tree (Terminalia tomentosa) in a Sal (Shorea robusta) mixed deciduous forest in the Kamdi Biological Corridor, Banke District, State No. 5, Nepal. Both individuals were captured, weighed and measured (Table 1), and released at the original site of capture.

The habitat (Fig. 2) appears to be more mesic and densely vegetated than that at other localities where this species is known to occur. However, the mixed hardwood forests in the lower Sivalik Hills within the corridor are drained only by intermittent streams and represent the driest mountain ecosystem in Nepal. Nocturnal December temperatures in the

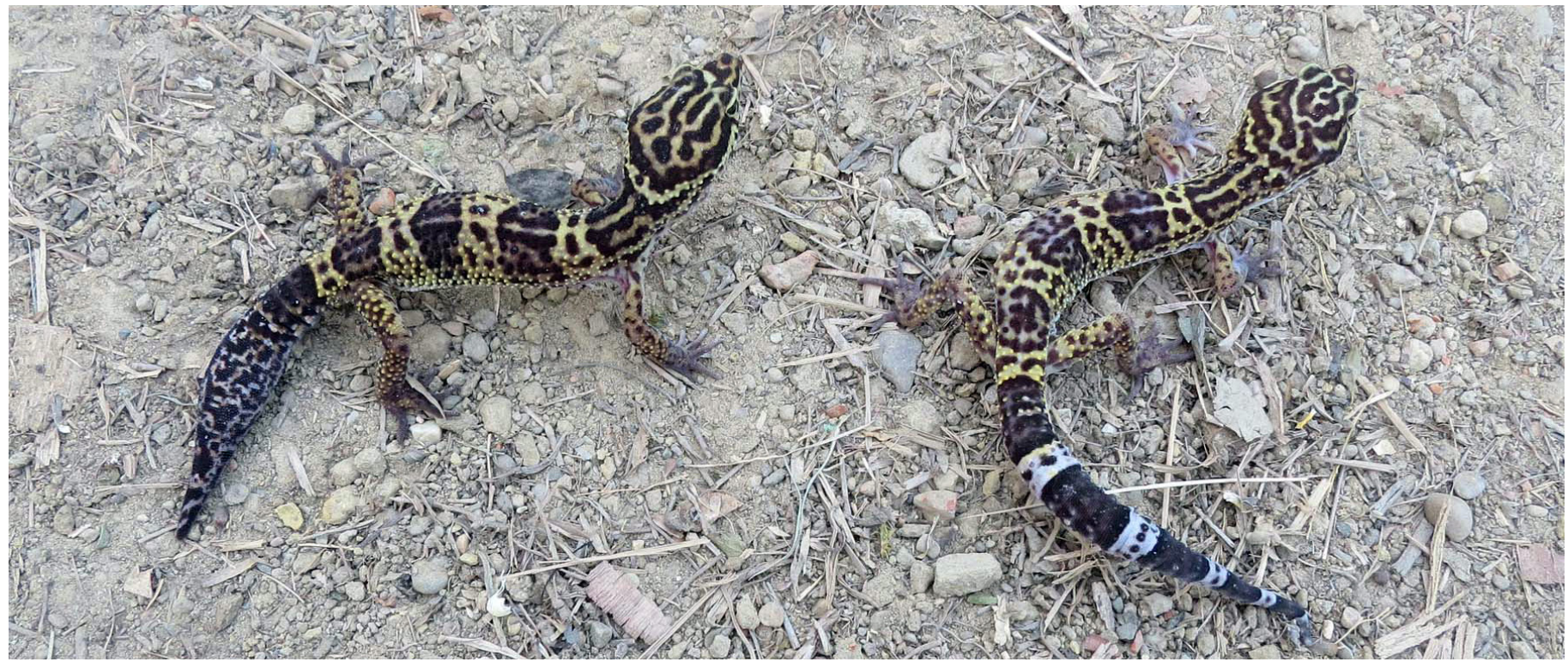

Fig. 1. Adult male Common Leopard Geckos (Eublepharis macularius) recorded in the Kamdi Biological Corridor, Banke District, Nepal. Photograph by Kul Bahadur Thapa. 
Table 1. Morphometric and meristic data for two male Common Leopard Geckos (Eublepharis macularius) from the Kamdi Biological Corridor, Banke District, Nepal. All measurements are in millimeters $(\mathrm{mm})$ except body weight, which is in grams $(\mathrm{g})$. Note that specimen No. 1 had an intact tail, whereas specimen No. 2 had a regenerated tail. We measured weight using a digital scale and morphometric measurements using a Vernier caliper (to the nearest $0.1 \mathrm{~mm}$ ). Morphometric and meristic data were according to Mirza et al. (2014): snout-vent length (SVL; from tip of snout to vent), tail length (TL; from vent to tip of tail), tail width (TW; maximum width of tail), interorbital distance (IOD; distance between the eyes), eye diameter (ED; greatest eye diameter), head height $(\mathrm{HH}$; maximum head height from occiput to underside of the jaws), head length (HL; posterior end of jaws to tip of snout), supralabials (SL), infralabials (IL), tympanum diameter (TD), pre-cloacal pores (PP), number of rows of granular dorsal tubercles at midbody (DTR), forelimb length from the axilla to tip of the fourth finger (FLL), hindlimb length from the groin to the tip of the fourth toe (HLL).

Kamdi Corridor, which connects the Banke National Park of Nepal and the Suhelwa Wildlife Sanctuary in Uttar Pradesh, India, are as low as $5^{\circ} \mathrm{C}$.

\begin{tabular}{lcc} 
Character & $\begin{array}{c}\text { Specimen } \\
\text { No. 1 }\end{array}$ & $\begin{array}{c}\text { Specimen } \\
\text { No. } 2\end{array}$ \\
\hline Weight & 27 & 26 \\
\hline SVL & 119 & 109 \\
\hline TL & 87 & 57 \\
\hline TW & 9 & 11 \\
\hline HL & 32 & 33 \\
\hline HW & 22 & 21 \\
\hline ED & 6 & 7 \\
\hline IOD & 10 & 10 \\
\hline NE & 7 & 7 \\
\hline SEL & 8 & 8 \\
\hline IN & 5 & 5 \\
\hline EE & 9 & 8 \\
\hline SL & 10 & 9 \\
\hline IL & 10 & 9 \\
\hline HH & 12 & 11 \\
\hline TD & 4 & 4 \\
\hline PP & 15 & 15 \\
\hline FLL & $15+19$ & $12+14$ \\
\hline HLL & $19+19$ & 18 \\
\hline & & 18 \\
\hline
\end{tabular}

We subsequently received photographic evidence of this species (Fig. 3) from Amar Darai (pers. comm.), who photographed two geckos on 18 April 2017 that were injured when

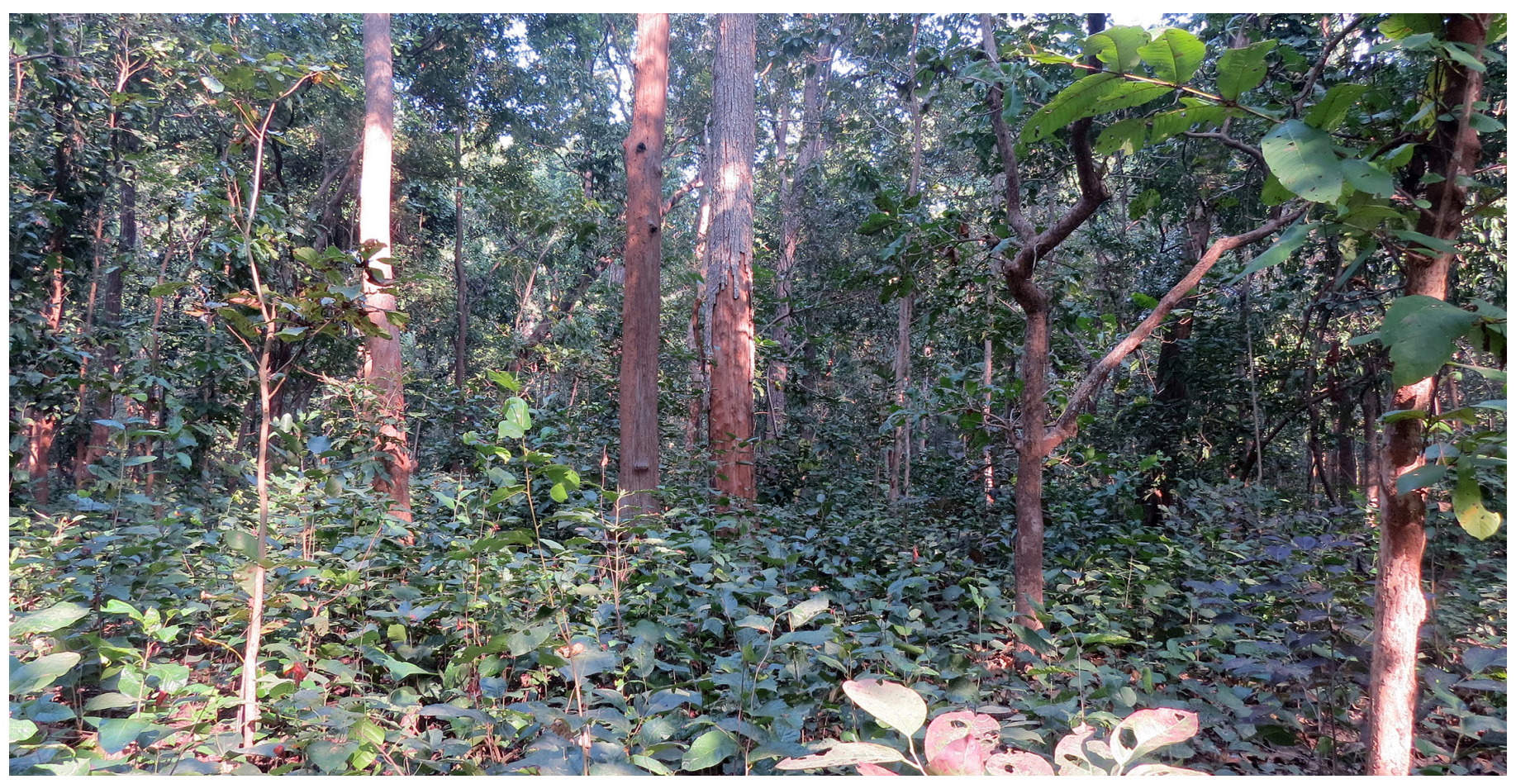

Fig. 2. Habitat of the Common Leopard Gecko (Eublepharis macularius) in the Kamdi Biological Corridor, Banke District, Nepal. Photograph by Kul Bahadur Thapa. 


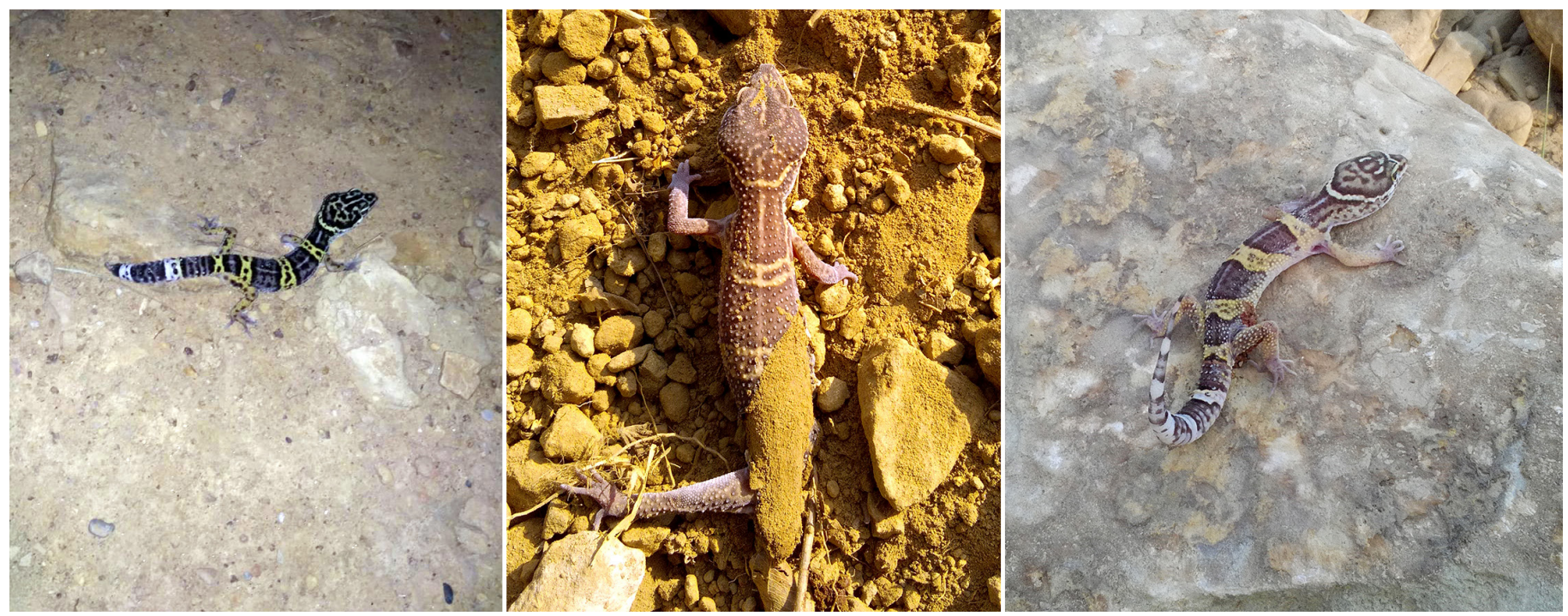

Fig. 3. Photographic vouchers of the Common Leopard Gecko (Eublepharis macularius) in Nepal from Gurvakot, Surkhet (left; photograph by Rup Saud) and from Sunwal, Parasi (center and right; photographs by Amar Darai).

excavated from under rocks in a dry river bed during gravel extraction near the village of Tilkana in Sunwal, Nawalparasi District, State No. 5, and from Rup Saud (pers. comm.), who found another gecko at $1700 \mathrm{~h}$ on 10 June 2018 on school grounds in Gurvakot, Surkhet District, Karnali State. These localities are ca. 180 and $80 \mathrm{~km}$ (aerial distance) from the Kamdi Biological Corridor, respectively (Fig. 4).

Because three other species of Eublepharis occur in India, we confirmed the identities of observed lizards as E. macu- larius by the presence of tuberculated subdigital lamellae and circular dorsal scales (absent in E. satpuraensis and E. fuscus), the lack of a nuchal loop extending anteriorly to the eyes and along supralabials to the tip of the snout (present in E. satpuraensis), and the presence of dorsal dark and pale bands with reticulations or spots (present in E. hardwickii) that do not correspond to our photographic vouchers (Mirza et al. 2014).

Eublepharis macularius has been recorded from Afghanistan, Pakistan, and northwestern India. The nearest

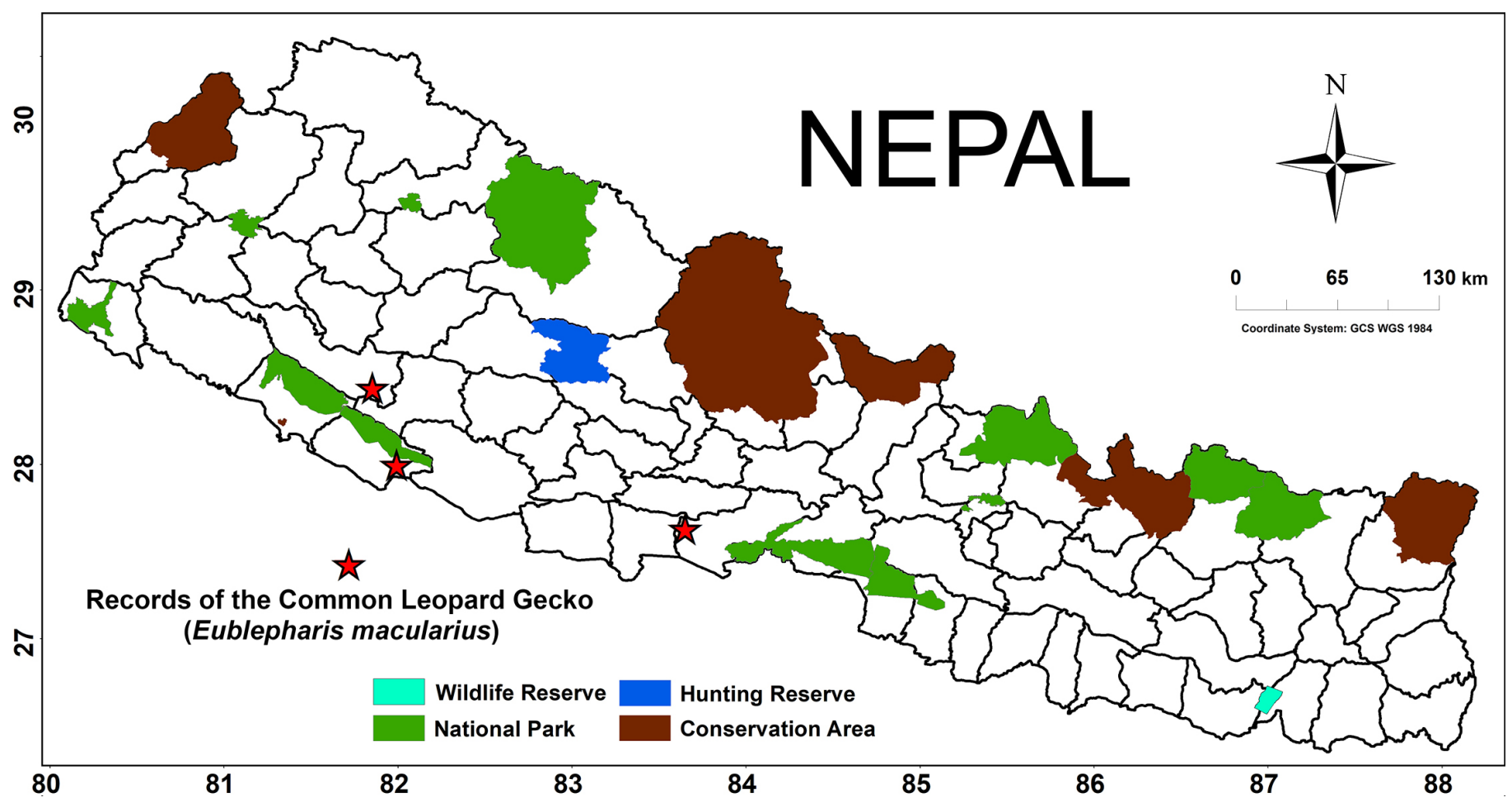

Fig. 4. Records of the Common Leopard Gecko (Eublepharis macularius) in Nepal. 
previously documented locality is Delhi, India (Sultana and Hussain 2010). These new records extend the species' global range approximately $500 \mathrm{~km}$ eastward. Common Leopard Geckos remained undetected in Nepal until now. This could be attributable to the secretive nocturnal nature of the species or the limited research on the herpetofauna in western Nepal (most herpetofaunal studies in Nepal have been concentrated in central and eastern parts of the country; Bhattarai et al. 2017). These new records from three different localities indicate that the species is likely to have much wider distribution in Nepal, including Banke National Park, which lies between the sites of these observations. Wildlife conservation in the Kamdi Biological Corridor dates only to the declaration of Banke National Park in 2010. The presence of E. macularius from the newly declared corridor reinforces its significance not only for the conservation of charismatic mammalian species but also for the cryptic and lower-priority herpetofauna of Nepal.

Eublepharis macularius has not been assessed for the IUCN Red List (IUCN 2018). These geckos are very popular in both the legal and illegal pet trade (Mirza et al. 2014). Frequent confiscations of geckos by customs officials at the Indo-Nepalese border are suggestive of a worrying threat to the conservation of this newly recorded species in Nepal. Until now, those confiscated geckos were believed to be of Indian origin, but it is now evident that Common Leopard Geckos from Nepal might also be involved in the illegal trade. Therefore, we intentionally have not provided the GPS locations of the new localities, all of which are outside protected areas. Logging in the Kamdi Biological Corridor and gravel excavation in Sunwal are observed threats to the species. We strongly recommend a detailed inventory of $E$. macularius in Nepal, concentrating on its distribution, conservation, and phylogenetic relationships among its apparently disjunct populations.

\section{Acknowledgements}

We thank the Department of Forests, Ministry of Forests and Environment, Himalayan Nature and National Trust for Nature Conservation for support in the field. Sharad Singh (Himalayan Nature) and Hem Sagar Baral (ZSL Nepal) provided encouragement. Sujan Khanal contributed to map preparation. Mark O'Shea and Peter Uetz provided valuable comments on an earlier draft of this manuscript.

\section{Literature Cited}

Bhattarai, S., C.P. Pokheral, B.R. Lamichhane, and N. Subedi. 2017. Herpetofauna of a Ramsar Site: Beeshazar and associated lakes, Chitwan National Park, Nepal. Reptiles \& Amphibians 24: 17-29.

Bonke, R., W. Böhme, K. Opiela, and D. Rödder. 2011. A remarkable case of cannibalism in juvenile Leopard Geckos, Eublepharis macularius (Blyth, 1854) (Squamata: Eublepharidae). Herpetology Notes 4: 211-212.

IUCN. 2018. The IUCN Red List of Threatened Species. Version 20181. <https://www.iucnredlist.org/>.

Mirza, A.Z., R.V. Sanap, D. Raju, A. Gawai, and P. Ghadekar. 2014. A new species of lizard of the genus Eublepharis (Squamata: Eublepharidae) from India. Phyllomedusa 13: 75-90.

Ota, H., M. Honda, M. Kobayashi, S. Sengoku, and T. Hikida. 1999. Phylogenetic relationships of eublepharid geckos (Reptilia: Squamata): A molecular approach. Zoological Science 16: 659-666.

Sultana, A. and M.S. Hussain. 2010. Geographic distribution: Eublepharis macularius (Indian Leopard Gecko). Herpetological Review 41: 512.

Uetz, P., P. Freed, and J. Hošek (eds.). 2018. The Reptile Database. <http://reptiledatabase.org/>. 